\title{
A Fast-Response Automated Gas Equilibrator (FaRAGE) for continuous in situ measurement of $\mathrm{CH}_{4}$ and $\mathrm{CO}_{2}$ dissolved in water
}

\author{
Shangbin Xiao ${ }^{1}$, Liu Liu ${ }^{2}$, Wei Wang ${ }^{1}$, Andreas Lorke ${ }^{1,3}$, Jason Woodhouse ${ }^{2}$, and Hans-Peter Grossart ${ }^{2,4}$ \\ ${ }^{1}$ College of Hydraulic \& Environmental Engineering, China Three Gorges University, 443002 Yichang, China \\ ${ }^{2}$ Department of Experimental Limnology, Leibniz Institute of Freshwater Ecology and Inland Fisheries, \\ 16775 Stechlin, Germany \\ ${ }^{3}$ Institute for Environmental Sciences, University of Koblenz-Landau, 76829 Landau, Germany \\ ${ }^{4}$ Institute of Biochemistry and Biology, Potsdam University, 14669 Potsdam, Germany
}

Correspondence: Liu Liu (liu.liu@igb-berlin.de) and Hans-Peter Grossart (hgrossart@igb-berlin.de)

Received: 11 February 2020 - Discussion started: 20 April 2020

Revised: 24 June 2020 - Accepted: 4 July 2020 - Published: 30 July 2020

\begin{abstract}
Biogenic greenhouse gas emissions, e.g., of methane $\left(\mathrm{CH}_{4}\right)$ and carbon dioxide $\left(\mathrm{CO}_{2}\right)$ from inland waters, contribute substantially to global warming. In aquatic systems, dissolved greenhouse gases are highly heterogeneous in both space and time. To better understand the biological and physical processes that affect sources and sinks of both $\mathrm{CH}_{4}$ and $\mathrm{CO}_{2}$, their dissolved concentrations need to be measured with high spatial and temporal resolution. To achieve this goal, we developed the Fast-Response Automated Gas Equilibrator (FaRAGE) for real-time in situ measurement of dissolved $\mathrm{CH}_{4}$ and $\mathrm{CO}_{2}$ concentrations at the water surface and in the water column. FaRAGE can achieve an exceptionally short response time $\left(t_{95} \%=12 \mathrm{~s}\right.$ when including the response time of the gas analyzer) while retaining an equilibration ratio of $62.6 \%$ and a measurement accuracy of $0.5 \%$ for $\mathrm{CH}_{4}$. A similar performance was observed for dissolved $\mathrm{CO}_{2}\left(t_{95} \%=10 \mathrm{~s}\right.$, equilibration ratio $67.1 \%$ ). An equilibration ratio as high as $91.8 \%$ can be reached at the cost of a slightly increased response time (16s). The FaRAGE is capable of continuously measuring dissolved $\mathrm{CO}_{2}$ and $\mathrm{CH}_{4}$ concentrations in the nM-to-sub $\mathrm{mM}$ $\left(10^{-9}-10^{-3} \mathrm{~mol} \mathrm{~L}^{-1}\right)$ range with a detection limit of sub$\mathrm{nM}\left(10^{-10} \mathrm{~mol} \mathrm{~L}^{-1}\right)$, when coupling with a cavity ring-down greenhouse gas analyzer (Picarro GasScouter). FaRAGE allows for the possibility of mapping dissolved concentration in a "quasi" three-dimensional manner in lakes and provides an inexpensive alternative to other commercial gas equilibrators. It is simple to operate and suitable for continuous monitoring with a strong tolerance for suspended particles. While
\end{abstract}

the FaRAGE is developed for inland waters, it can be also applied to ocean waters by tuning the gas-water mixing ratio. The FaRAGE is easily adapted to suit other gas analyzers expanding the range of potential applications, including nitrous oxide and isotopic composition of the gases.

\section{Introduction}

Despite the well-established perception of inland waters as a substantial source of atmospheric methane $\left(\mathrm{CH}_{4}\right)$ and carbon dioxide $\left(\mathrm{CO}_{2}\right)$ (Bastviken et al., 2011; Cole et al., 2007; Tranvik et al., 2009), the magnitude of these greenhouse gases remains uncertain owing to the fact that some key processes affecting $\mathrm{CH}_{4}$ (e.g., bubbling) and $\mathrm{CO}_{2}$ budget are still poorly constrained (Saunois et al., 2019). Most freshwater lakes and reservoirs are often oversaturated with $\mathrm{CH}_{4}$ and $\mathrm{CO}_{2}$ (relative to the atmosphere), and their distributions are characterized by high spatio-temporal heterogeneity (Hofmann, 2013). Point-based and short-term measurements can result in biases in estimating diffusive $\mathrm{CH}_{4}$ flux (Paranaíba et al., 2018). Thus, resolving the spatio-temporal dynamics of both dissolved $\mathrm{CH}_{4}$ and $\mathrm{CO}_{2}$ is a prerequisite for a better understanding of the production and loss processes of these gases in freshwater lakes.

The distribution of $\mathrm{CH}_{4}$ and $\mathrm{CO}_{2}$ in lakes is often characterized by pronounced vertical and horizontal concentration gradients, which often coincides with the position of the thermocline. In many deep stratified lakes, a sharp vertical gradi- 
ent of $\mathrm{CH}_{4}$, for instance, below the thermocline can develop in the anoxic hypolimnion (mM range) (Encinas Fernández et al., 2014; Liu et al., 1996). In contrast, in some stratified lakes with a fully oxygenated hypolimnion $\mathrm{CH}_{4}$ can accumulate above the thermocline ( $\sim \mu \mathrm{M}$ range) (Grossart et al., 2011; Donis et al., 2017; Günthel et al., 2019). In addition to formation processes that lead to $\mathrm{CH}_{4}$ accumulation, the concentration of dissolved $\mathrm{CH}_{4}$ is also regulated by losses due to oxidation and emission to the atmosphere (Bastviken et al., 2004; Juutinen et al., 2009). Emission rates, in particular, are highly variable dependent on turbulence induced by wind or convective mixing (Read et al., 2012; Vachon and Prairie, 2013). Vertical distributions of $\mathrm{CH}_{4}$ and $\mathrm{CO}_{2}$ can further confound the contribution of littoral sediments, which can result in distinct horizontal gradients of $\mathrm{CO}_{2}$ and $\mathrm{CH}_{4}$ (Murase et al., 2003). Accounting for horizontal gradients is therefore critical as lateral transport may account for a proportion of the epilimnetic $\mathrm{CH}_{4}$ peak observed in pelagic waters (Hofmann et al., 2010; Fernández et al., 2016; Murase et al., 2005; Peeters et al., 2019).

Spatial distributions of $\mathrm{CH}_{4}$ and $\mathrm{CO}_{2}$ in aquatic systems vary over time, particularly as factors which control their production, consumption and loss to the atmosphere fluctuate. Concentrations of $\mathrm{CH}_{4}$ and $\mathrm{CO}_{2}$ in lakes demonstrate profound seasonality, driven primarily by thermal stratification (Encinas Fernández et al., 2014) and phytoplankton dynamics (Günthel et al., 2019). While the build-up of hypolimnetic $\mathrm{CH}_{4}$ storage is a slow process that is closely related to the development of lake hypoxia, epilimnetic $\mathrm{CH}_{4}$ and $\mathrm{CO}_{2}$ can be highly variable even at a daily basis as they are strongly affected by phytoplankton dynamics (Günthel et al., 2019; Hartmann et al., 2020; Bižić et al., 2020). In addition, storms can act as another driver for short-term dissolved gas dynamics in the lake because they often contribute to higher evasion rates caused by strong vertical turbulent mixing (Zimmermann et al., 2019) and enhanced horizontal transport (Fernández et al., 2016). While the seasonal patterns of dissolved $\mathrm{CH}_{4}$ and $\mathrm{CO}_{2}$ concentration in lake water seem recurrent and can be simulated (Stepanenko et al., 2016), the unpredictable effects of short-term biological dynamics and storm events can present a challenge in modeling the dynamics of greenhouse gases in lakes.

While there is an urgent need to resolve the spatiotemporal variability of $\mathrm{CH}_{4}$ in large water bodies (e.g., lakes), we recognize limitations in the available methodology. Like most gases in the dissolved phase, $\mathrm{CH}_{4}$ and $\mathrm{CO}_{2}$ cannot be measured directly in water. Instead, a carrier gas (synthetic air or at air concentration) is added to achieve (full/partial) gas-water equilibration. The headspace gas sample is then measured with a gas spectrometer and the concentration of targeted gas can be calculated according to Henry's law (Magen et al., 2014). To save sampling effort, continuous gas equilibration devices have been developed, which generally can be classified into four categories: (1) membrane type (Schlüter and Gentz, 2008; Boulart et al.,
2010; Gonzalez-Valencia et al., 2014; Hartmann et al., 2018) - gases are extracted from water using a gas-permeable membrane; (2) marble type (Frankignoulle et al., 2001; Santos et al., 2012) - gas exchange is enhanced by pumping water through marbles that increase the gas-water contact area; (3) bubble type (Schneider et al., 1992; Körtzinger et al., 1996; Gülzow et al., 2011) - dissolved gases are stripped out by bubbling the water sample; (4) showerhead type (Weiss type) (Johnson, 1999; Rhee et al., 2009; Li et al., 2015) - water is pumped from the top and then mixed with a circulated headspace carrier gas. A full evaluation of the performance of these devices was provided in a recent review (Webb et al., 2016), where the most important parameter, response time, was found to vary between 2 and $34 \mathrm{~min}$ for dissolved $\mathrm{CH}_{4}$. While it is already encouraging, improvements are expected to further shorten the response time.

Driven by the need to resolve temporal and spatial variability of dissolved $\mathrm{CH}_{4}$ and $\mathrm{CO}_{2}$ in inland waters with sufficient precision, we developed a novel, low-cost equilibrator to achieve fast gas-water equilibration. The Fast-Response Automated Gas Equilibrator (FaRAGE) can be coupled with a portable gas analyzer, which makes it perfect for field use. Here, the performance of the FaRAGE is evaluated by investigating its response time, detection limit and equilibration ratio. Although FaRAGE has been developed for inland waters, it can be also adapted for oceanographic applications. Applications are provided exemplarily to demonstrate the potential of the FaRAGE for improving our understanding of the spatial distribution and temporal dynamics of dissolved $\mathrm{CH}_{4}$ and $\mathrm{CO}_{2}$ in inland waters.

\section{Materials and methods}

\subsection{Device description}

The design of the FaRAGE is modified from two types of equilibrators: bubble type (Schneider et al., 1992) and Weiss type (Johnson, 1999). In contrast to the traditional bubble-type and Weiss-type equilibrators that create a largevolume headspace and circulate air back to the headspace, the FaRAGE is a flow-through system that adds gas flow into a constant water flow to produce a minimal headspace for continuous concentration measurement of $\mathrm{CO}_{2}$ and $\mathrm{CH}_{4}$ dissolved in water.

The operation principle of the FaRAGE is depicted in Fig. 1, and technical drawings of the main parts of the prototype are provided in Fig. S1 in the Supplement. A list of information on suppliers and the cost of each part can be found in Table S1 in the Supplement. A mass flow controller (SIERRA C50L, Netherlands) is used to generate a constant carrier gas (normal air/synthetic air) flow $\left(1 \mathrm{~L} \mathrm{~min}^{-1}\right)$ from a compressed air tank coupled with a pressure regulator. Water samples are taken continuously using a peristaltic pump $\left(500 \mathrm{~mL} \mathrm{~min}^{-1}\right)$, and the flow is monitored using a flow me- 
ter (Brooks Instrument, Germany). The two flows mix in a gas-water mixing unit and then travel through a coiled hose for further gas-water turbulent mixing. In the gas-water mixing unit (modified from a $10 \mathrm{~mL}$ plastic syringe), a jet flow is created by adapting narrowed tubing $(2 \mathrm{~mm}$ inner diameter) to the water pumping hose ( $3.2 \mathrm{~mm}$ inner diameter). Degassing occurs when the jet flow enters the chamber with a sudden enlarged diameter $(14 \mathrm{~mm})$. Degassing is further enhanced by micro-bubbles that are generated by a bubble diffusor attached to the carrier gas hose (inside the plastic syringe). The gas-water mixture flows through the $2 \mathrm{~m}$ long Tygon tube ( $3.2 \mathrm{~mm}$ inner diameter), where additional equilibration occurs. The flow is finally introduced to a gaswater separation unit (a $30 \mathrm{~mL}$ plastic syringe) where the headspace gas is separated from the water. In this chamber, water falls down freely to the bottom, while the headspace gas is taken directly to a greenhouse gas analyzer $\left(1 \mathrm{~L} \mathrm{~min}^{-1}\right.$ gas pumping rate; GasScouter G4301, Picarro, USA). A $2 \mathrm{~m}$ long Tygon tube ( $3.2 \mathrm{~mm}$ inner diameter) is attached to the top of the chamber for venting excess gas flow while stabilizing gas pressure in the headspace. The bottom water is discharged back to the lake using another peristaltic pump $\left(500 \mathrm{~mL} \mathrm{~min}^{-1}\right)$. To protect the gas analyzer from damaging high water vapor content, a Teflon membrane filter (pore size $0.2 \mu \mathrm{m}$ ) is placed before the gas intake (resulting in a $\sim 210 \mathrm{~mL} \mathrm{~min}^{-1}$ reduction in flow rate of the gas sample, which is vented from the bypass at the top of the gas separation unit). A desiccant (a $20 \mathrm{~mL}$ plastic syringe filled with dried silicone beads) is used to reduce moisture concentration when attaching to a Picarro G2132-i isotope analyzer (Picarro, USA), in which $<1 \%$ moisture level is required for $\delta^{13} \mathrm{C}_{-} \mathrm{CH}_{4}$ measurement. The temperature of the water sample at the point of equilibration with the headspace gas is monitored using a fast thermometer (precision $0.001{ }^{\circ} \mathrm{C}$, $1 \mathrm{~Hz}$, TR-1050, RBR, Canada) attached to the end of the water-discharging hose.

In addition to Gas Scouter from Picarro, two additional widely used models of greenhouse gas analyzers were tested. They are the Ultraportable Los Gatos (Los Gatos Research, USA) and stable isotopic $\mathrm{CH}_{4}$ (G2132-i, Picarro, USA) analyzers. The main technical details of all three tested gas analyzers are listed in Table S2.

\subsection{Laboratory validation}

The FaRAGE prototype was first tested intensively in the laboratory to determine both the equilibration ratio and response time. The tests were performed for both $\mathrm{CH}_{4}$ and $\mathrm{CO}_{2}$ with a GasScouter G4301 (Picarro, USA), which measures both gases simultaneously. The equilibration ratio is defined as the concentration of the gas at the outlet of the gas equilibrator in comparison to the equilibrium concentration (full gas-water equilibration). The equilibration ratio was established across a range of stock solutions (nano-to-milli molar dissolved gas concentrations). These standard solutions were

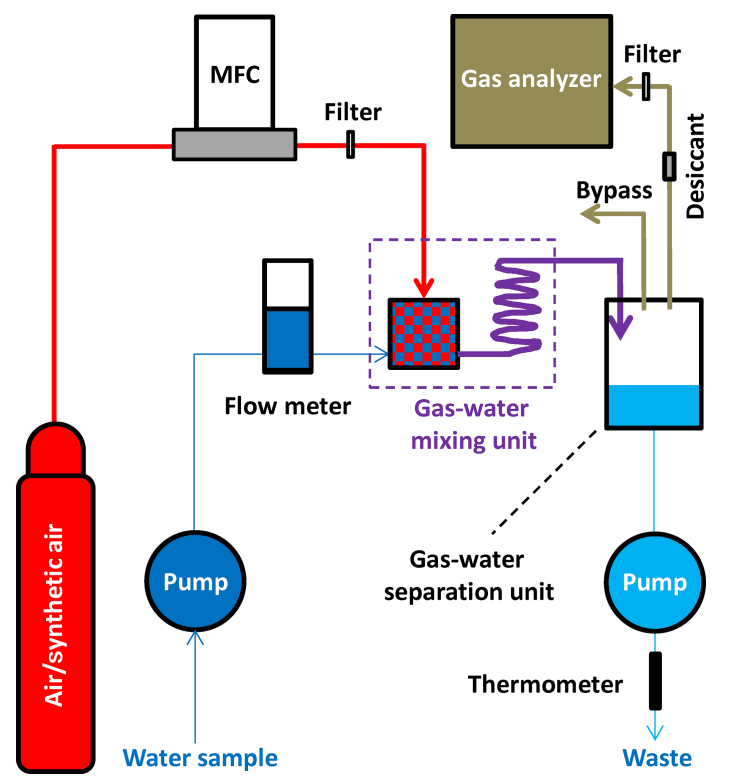

Figure 1. Schematic design of the FaRAGE. The components include an air tank containing compressed carrier gas (air or synthetic air) with a pressure regulator, a mass flow controller (MFC) for generating constant carrier gas flow, two peristaltic pumps for taking and discharging water, respectively, a flow meter for monitoring water sample flow, a gas-water mixing unit, a gas-water separation unit, a gas analyzer, and a thermometer for measuring water temperature at phase equilibration. A Teflon membrane filter is placed after the MFC and another is added before the gas analyzer to protect it from being flooded. A desiccant is used to dry the gas flowing to the gas analyzer (if a Picarro isotopic analyzer is used). The red color marks the flow of carrier gas, dark blue line indicates the water sample, purple line shows the flow of the gas-water mixture, the light brown line shows the flow of the gas sample (after partial equilibration) and the light blue line depicts the water discharged back to the lake. The thickness of the lines scales with the gas-water flow rates. The arrows show the flow directions.

prepared by adding different amounts of either $\mathrm{CH}_{4}$ or $\mathrm{CO}_{2}$ into a $200 \mathrm{~mL}$ headspace of a $2 \mathrm{~L}$ Schott bottle filled with Milli-Q water. The exact concentrations in these solutions were tested with the manual headspace method: a $400 \mathrm{~mL}$ headspace was created in a $500 \mathrm{~mL}$ plastic syringe with nitrogen gas. The gas concentration of the headspace gas was then measured using GasScouter G4301. At the same time, dissolved $\mathrm{CH}_{4}$ and $\mathrm{CO}_{2}$ concentrations of these standard solutions were measured with the FaRAGE for at least 2 min and an average was calculated from more than 60 individual data points. We directly compared dissolved gas concentrations measured using the two different methods, i.e., our equilibrator and manual headspace method.

The response time of the device was investigated by switching the water sample inlet between two water samples with different concentrations of either $\mathrm{CH}_{4}$ or $\mathrm{CO}_{2}$. Triplicated measurements were performed. An exponential fit was applied to the concentration change curve and the response 
time was determined as the time needed to reach $95 \%$ of the final concentration.

The effect of water-to-gas mixing ratio on equilibration ratio and response time of the device was investigated. By fixing the carrier gas flow rate to $1 \mathrm{~L} \mathrm{~min}^{-1}$, the water-to-gas mixing ratio was varied from $0.04,0.08,0.12,0.15,0.24$, $0.29,0.36,0.43$ and 0.5 by adjusting the water sample flow rate. The effect of tube length on the performance of the device was also examined by adapting 1, 2, 4.4, 8.4 and $13 \mathrm{~m}$ Tygon tubes onto the gas-water mixing unit. For all these tests, triplicated measurements of the equilibration ratio and response time were performed corresponding to different mixing ratios, and the mean values were used for analysis.

Tests were performed to investigate the performance of the device when adapting to two other types of gas analyzers. As the equilibration ratio is unaffected by the model of gas analyzers, only response time was determined. This was done by fixing carrier gas and water sample flow rates to 1 and $0.5 \mathrm{~L} \mathrm{~min}^{-1}$, respectively. The surplus gas was vented to the air as Ultraportable Los Gatos and Picarro G2132-i have gas intake flow rates of only 500 and $25 \mathrm{~mL} \mathrm{~min}^{-1}$, respectively. The effect of desiccant on response time of Picarro G2132-i was checked by measuring gas samples with and without a desiccant installed.

\subsection{Field tests}

Four lakes in Germany were chosen for field tests. Lake Stechlin is a deep meso-oligotrophic lake with a maximum depth of $68 \mathrm{~m}$ and Lake Arend is a eutrophic lake with a maximum depth of $48 \mathrm{~m}$. Pronounced $\mathrm{CH}_{4}$ peaks in the epilimnion of Lake Stechlin have been previously reported that were measured with two different methods (manual headspace method in Grossart et al., 2011, and Tang et al., 2014; membrane-based gas equilibrator in Hartmann et al., 2018). This makes it ideal for our testing purpose. While $\mathrm{CH}_{4}$ profiles at Lake Arend have never been reported, the metalimnetic oxygen minimum in the lake observed during summer (Kreling et al., 2017) renders it interesting for $\mathrm{CH}_{4}$ profiling throughout the entire water column. Additionally, we selected both eutrophic lakes with an anoxic hypolimnion (Lake Großer Pälitz and Lake Zotzen), where $\mathrm{CH}_{4}$ and $\mathrm{CO}_{2}$ can accumulate during the period of thermal stratification. Measurements were conducted in these two lakes to test the capability of FaRAGE to measure water with high dissolved $\mathrm{CH}_{4}$ and $\mathrm{CO}_{2}$ concentrations.

Due to the high potential of the FaRAGE for real-time in situ measurement of dissolved $\mathrm{CH}_{4}$ and $\mathrm{CO}_{2}$ concentrations, we explored potential field applications. These field tests included depth profiling of dissolved $\mathrm{CH}_{4}$ concentrations in the four lakes and investigations of the horizontal distribution of surface-dissolved $\mathrm{CH}_{4}$ and $\mathrm{CO}_{2}$ concentrations across the entire Lake Stechlin. For the first application, a fast-response CTD (conductivity, temperature and depth) profiler (XR-620 CTD+, RBR, Canada) was mounted onto a winch with a $30 \mathrm{~m}$ long water hose $(4 \mathrm{~mm}$ inner diameter) attached. The CTD profiler with the hose was lowered down continuously at a constant speed $\left(1 \mathrm{~m} \mathrm{~min}^{-1}\right)$. The exact depth and temperature of sampled water can be extracted from the CTD profiler by correcting for the travel time of water sample flow in the hose. For the spatial mapping, a GPS antenna (Taoglas, AA.162, USA) was attached to the Picarro gas analyzer. The water intake was submerged $0.5 \mathrm{~m}$ below the water surface together with the CTD profiler and fixed to one side of the boat. The boat was driven at a constant speed of $5 \mathrm{~km} \mathrm{~h}^{-1}$.

\subsection{Theoretical background and data processing}

The FaRAGE shares a similar working principle to the Weiss-type gas equilibrator described by Johnson (1999). The theoretical background and equations are provided in Sect. S3.

A simplified calculation is described by referring to the manual headspace method. In principle the gas-water mixture is analogous to the static headspace method, with the final gas concentration in the gas phase assumed to reach a full equilibrium with that dissolved in the aqueous phase. Therefore, by specifying the mixing ratio of air and water, the total mass of $\mathrm{CH}_{4}$, for instance, can be calculated by summing up the $\mathrm{CH}_{4}$ in the headspace with the dissolved $\mathrm{CH}_{4}$ (at equilibrium according to Henry's law, which is temperature and pressure dependent) in the aqueous phase and subtracting the mass of background $\mathrm{CH}_{4}$ (from the carrying gas with known concentration). The dissolved gas concentration is then expressed as the volumetric concentration of the total net mass of either $\mathrm{CH}_{4}$ or $\mathrm{CO}_{2}$ in the dissolved phase in the given sample volume. A separated exemplary calculation sheet (Excel file S5) is provided, which allows for correction for temperature and pressure change (Goldenfum, 2010).

As the equilibration is only partially reached $(<92 \%)$, a correction coefficient is needed. This can be obtained by measuring the water samples with known concentrations across a large gradient. By referring to the results measured with the manual headspace method assuming full equilibration (Magen et al., 2014), an equation for precise correction of the measured dissolved gas concentrations can be obtained.

\section{Results and discussion}

\subsection{Detection limit, equilibration ratio and response time}

The FaRAGE is capable of achieving a high gas equilibration ratio. We observed a high correlation $\left(R^{2}=1000, p<0.01\right)$ between the concentrations obtained using the headspace method and those measured using the FaRAGE (Fig. 2a) across a wide range of dissolved $\mathrm{CH}_{4}$ and $\mathrm{CO}_{2}$ concentra- 
tions. The measurement accuracy is $0.5 \%$ (standard deviation in relation to final concentration) once a stable plateau has been reached (Fig. 2c). For $\mathrm{CH}_{4}$, the FaRAGE reaches a high equilibration ratio $(62.6 \%)$ and ensures a rapid response. The determined response time $t_{95} \%$ is only $12 \pm 1 \mathrm{~s}$ when switching from low-to-high (nano-to-sub micro molar) dissolved $\mathrm{CH}_{4}$ concentrations, while the $t_{95} \%$ is a little longer $(15 \pm 2 \mathrm{~s})$ when switching from high-to-low concentration (Fig. 2c). For the current design specifications that allow for a high equilibration ratio, the detection is theoretically limited by the sensitivity of the coupled gas analyzer. In the lab tests, a clear response was observed at least for $\mathrm{CH}_{4}$ concentration at air saturation $(5.5 \mathrm{nM}$ inside the lab building). The measurable $\mathrm{CH}_{4}$ concentrations should be at least sub-nM $\left(10^{-10} \mathrm{~mol} \mathrm{~L}^{-1}\right)$ given the high performance of cavity ring-down gas analyzers. This is more than sufficient for applications in inland waters, where dissolved $\mathrm{CH}_{4}$ concentrations are often above air saturation. Despite $\mathrm{CO}_{2}$ (Weiss, 1974) being an order of magnitude more soluble in water than $\mathrm{CH}_{4}$ (Wiesenburg and Guinasso, 1979), similar performances of the FaRAGE were observed when measuring dissolved $\mathrm{CO}_{2}$. An equilibration ratio of $67.1 \%$ (Fig. 2b) was achieved with a fast response (Fig. $2 \mathrm{~d} ; t_{95} \%=10 \pm 2$ and $15 \pm 2$ for low-to-high and high-to-low, respectively) when a $2 \mathrm{~m}$ mixing tube was used.

The response time for the FaRAGE results from two components: (1) the response of the gas analyzer to changes in gas concentration and (2) the physical gas-water exchange process. The response time for the gas analyzer is $5 \mathrm{~s}$ when the $\mathrm{CH}_{4}$ concentration increases (Fig. S2). The FaRAGE itself needs $<10$ s to reach $95 \%$ of the final steady-state concentration.

Equilibration ratio and response time of the FaRAGE are not sensitive to the water-to-gas mixing ratio (Fig. 3a) but rather to the length of the tube attached after the gas-water mixing unit (Fig. 3c). A small effect of the increased waterto-gas mixing ratio was also observed on the equilibration ratio. The increased water-to-gas mixing ratio did not substantially change the response time of the device $(9.5 \pm 1.5 \mathrm{~s}$ for low-to-high and 13.9 $\pm 2.4 \mathrm{~s}$ for high-to-low, respectively). This is in contrast to other types of equilibrators in which an increase in water-to-gas mixing ratio was found to result in a faster response (Webb et al., 2016). However, a sharp enhancement of the equilibration ratio was observed due to the extended length of the tube for the gas-water mixing unit. A $91.8 \%$ equilibration ratio can be achieved by extending the tube length to $13 \mathrm{~m}$, while extended response times are expected (low-to-high $17 \mathrm{~s}$ and high-to-low $47.5 \mathrm{~s}$, respectively). Increases in response time were notable when the tube length exceeded $13 \mathrm{~m}$ and were considered excessive at a tube length of $18 \mathrm{~m}$ (Fig. 3c and d). Further enhancement of the equilibration ratio was thus not possible when a longer tube (e.g., $18 \mathrm{~m}$ ) was used. The gas flow rate cannot be stabilized at $1 \mathrm{~L} \mathrm{~min}^{-1}$ due to the increased resistance in response to the further extension of tube length. Equilibration ratio
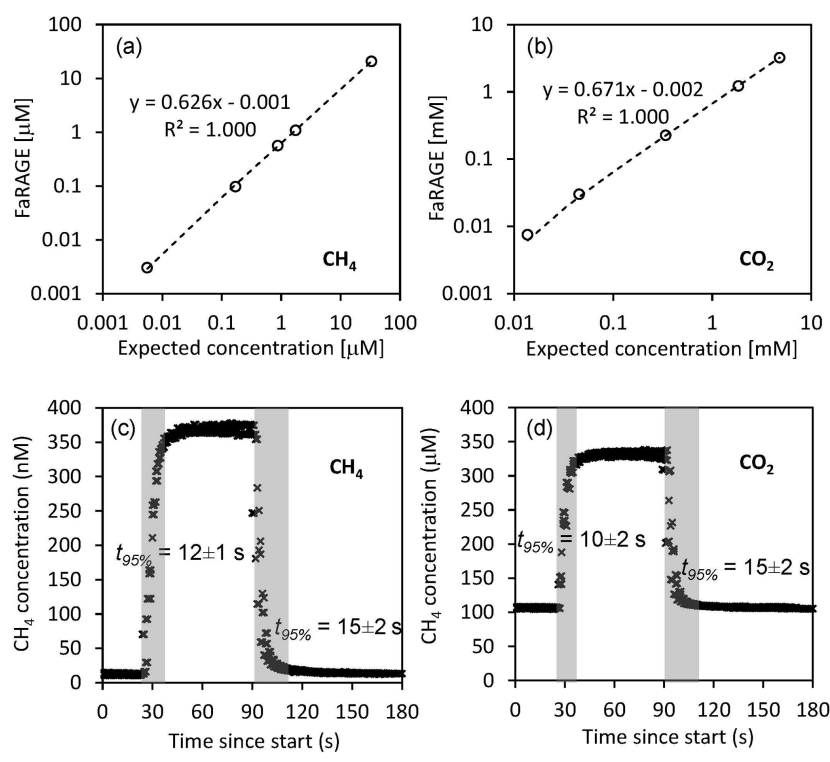

Figure 2. Performance of the Fast-Response Automated Gas Equilibrator (FaRAGE with a $2 \mathrm{~m}$ tube in the gas-water mixing unit) for both dissolved $\mathrm{CH}_{4}$ and $\mathrm{CO}_{2}$. (a, b) Correction equations for dissolved $\mathrm{CH}_{4}$ and $\mathrm{CO}_{2}$, respectively, by referring FaRAGE measurements to expected concentrations measured using the manual headspace method. The dashed lines show a linear fit and the equations are shown next to the lines. Note that in the two graphs both axes are log transformed. (c, d) Exemplary response time of FaRAGE for low-to-high and high-to-low concentration changes (water-to-gas mixing ratio 0.5 ). Triplicated tests were performed and the average response time was taken at the time point when $95 \%$ of the final concentration was reached.

and response time were affected by the length of the tube after the gas-water mixing in a similar way to $\mathrm{CH}_{4}$ (Fig. $3 \mathrm{~b}$ and $\mathrm{d}$ ), with only one exception in the response time when the dissolved $\mathrm{CO}_{2}$ concentration changed from high to low. The response time increased linearly $\left(R^{2}=0.910, p<0.01\right)$ from 11 to $18 \mathrm{~s}$ in response to the increase in the water-to-gas ratio from 0.04 to 0.5 .

As shown in Table S2 and Fig. S2, the fast response of the FaRAGE is partly due to the extremely fast response of the Picarro Gas Scouter. Tests were performed by adapting the FaRAGE to two other greenhouse gas analyzers (Ultraportable Los Gatos and Picarro G2132-i), and the response times are listed in Table S3. Comparisons were made in Webb et al. (2016) and Hartmann et al. (2018), where both $\mathrm{CH}_{4}$ and $\delta^{13} \mathrm{C}-\mathrm{CH}_{4}$ were measured using a Picarro G2201-i (Picarro, USA). Here we used a similar Picarro stable isotopic gas analyzer (Picarro G2132-i) and unified all previous reported response times $\tau$ to $t 95 \%$ by applying the equation $t_{95} \%=3 \tau$. The comparison between up-to-date previous studies and this study (Table S4) demonstrated the extraordinarily fast response relative to all existing gas equilibration devices. A $53 \mathrm{~s}$ response time was achieved when 

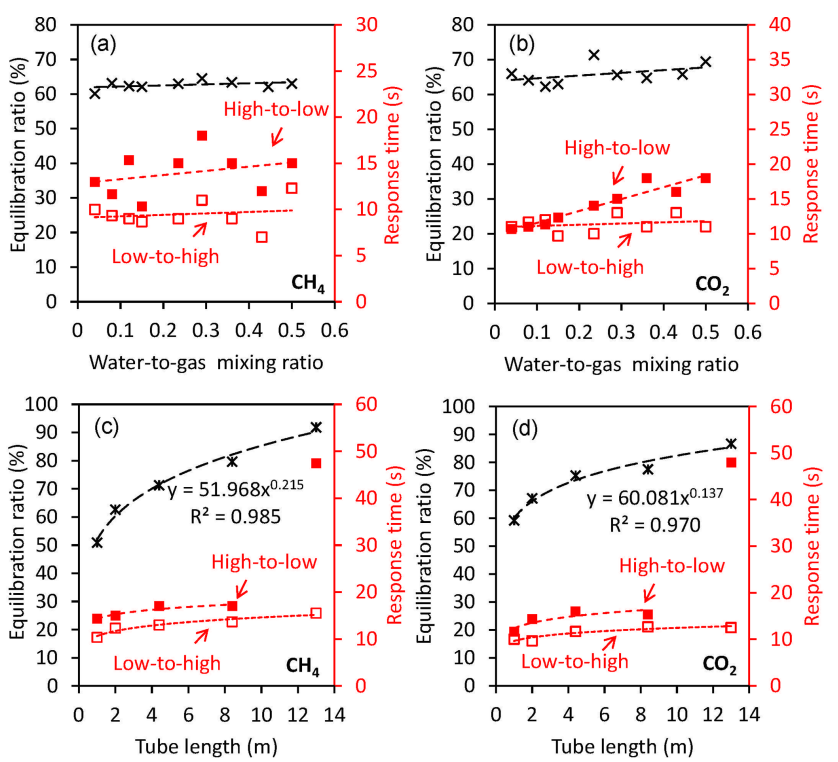

Figure 3. Factors affecting the performance of the gas equilibrator for both dissolved $\mathrm{CH}_{4}$ and $\mathrm{CO}_{2}$. (a, b) Equilibration ratio and response time in response to changing water-gas mixing ratio (with a $2 \mathrm{~m}$ tube in the gas-water mixing unit). Black cross symbols are equilibration ratios, and low-to-high and high-to-low response times are represented by red open and solid squares, respectively. $(\mathbf{c}, \mathbf{d})$ Equilibration ratio and response time in response to changing tube length of the gas-water mixing unit (with a fixed water-to-gas mixing ratio of 0.5 ). Black cross symbols are equilibration ratios, and low-to-high and high-to-low response times are represented by red open and solid squares, respectively.

the FaRAGE was adapted to the Picarro G2132-i, which is substantially faster than previously reported (171-6744 s).

\subsection{Depth profiles of dissolved $\mathrm{CH}_{4}$ and $\mathrm{CO}_{2}$ from multiple lakes}

Good agreement was observed between depth profiles of dissolved $\mathrm{CH}_{4}$ and $\mathrm{CO}_{2}$ concentration measured using the FaRAGE and the manual headspace method (Fig. 4). The occurrence of a maximum in the vertical profile of dissolved $\mathrm{CH}_{4}$ concentration in the upper layer of Lake Stechlin (Fig. 4a) is consistent with previous observations (Grossart et al., 2011; Tang et al., 2014; Hartmann et al., 2018). In Lake Arend we also observed a $\mathrm{CH}_{4}$ peak (Fig. 4a), although the overall concentration was lower. The opposite was observed at Lake Großer Pälitz and Lake Zotzen (Fig. 4c) with an anoxic hypolimnion, where the dissolved $\mathrm{CH}_{4}$ concentration was 3 orders of magnitude higher than in the epilimnion. Higher dissolved $\mathrm{CO}_{2}\left(10^{2}-10^{3} \mu \mathrm{M}\right)$ was also observed in the hypolimnion of these two lakes (Fig. 4d) in comparison to Lake Stechlin and Lake Arend ( $<10^{2} \mu \mathrm{M}$ in Fig. $\left.4 \mathrm{~b}\right)$.

In contrast to the headspace method, the FaRAGE allowed for profiles of $\mathrm{CH}_{4}$ and $\mathrm{CO}_{2}$ to be described at a high vertical resolution, similarly to that obtained with more sophisti-
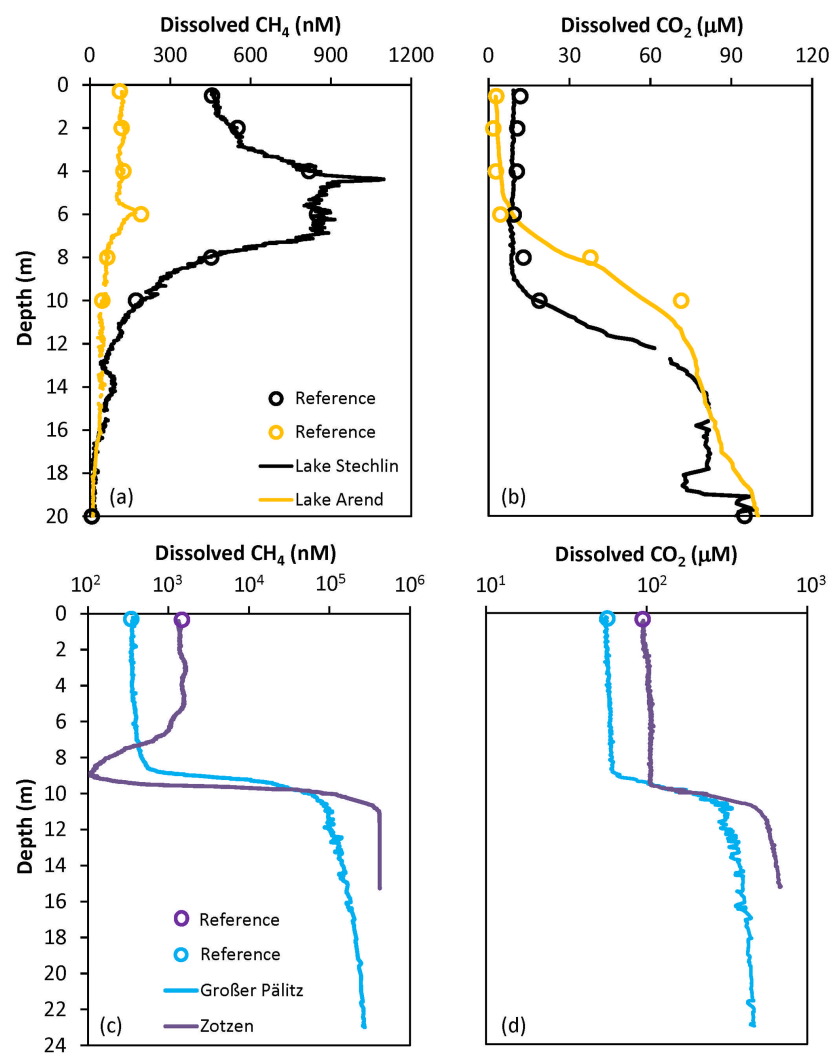

Figure 4. Depth profiles of dissolved $\mathrm{CH}_{4}$ and $\mathrm{CO}_{2}$ concentration from a set of lakes in Germany: (a, b) Lake Stechlin and Lake Arend with an oxygenated hypolimnion in summer; $(\mathbf{c}, \mathbf{d})$ Lake Großer Pälitz and Lake Zotzen, both with an anoxic hypolimnion in October. Note that the log-transformed $x$ axis is used in $(\mathbf{c}, \mathbf{d})$. References using the headspace method are designated as red open circles and measurements using the FaRAGE are shown as solid lines.

cated membrane filter equilibrators (Hartmann et al., 2018; Gonzalez-Valencia et al., 2014). The FaRAGE was capable of resolving differences in dissolved $\mathrm{CH}_{4}$ and $\mathrm{CO}_{2}$ concentrations in lake water at decimeter resolution with ease. Whilst care should be taken to ensure the sampling hose moves smoothly and slowly through the water column, continuous profiling of a $20 \mathrm{~m}$ deep lake can be completed in $30 \mathrm{~min}$. This is a big advantage since in situ $\mathrm{CH}_{4}$ concentrations can vary at very short timescales (hours to days) subject to internal production, oxidation, weather conditions, etc. (cf. Hartmann et al., 2020).

\subsection{Resolving spatial variability of dissolved $\mathrm{CH}_{4}$ and $\mathrm{CO}_{2}$ concentrations}

We confirmed the capability of the FaRAGE to operate continuously over a $7 \mathrm{~h}$ period without notable decreases in performance (Fig. 5a and b). Benefitting from its fast response rate, surface water dissolved $\mathrm{CH}_{4}$ and $\mathrm{CO}_{2}$ concentrations across the $4.52 \mathrm{~km}^{2}$ Lake Stechlin were mapped with great detail within $1 \mathrm{~d}$ (Fig. $5 \mathrm{c}$ and d). During the cruise, 10 ref- 

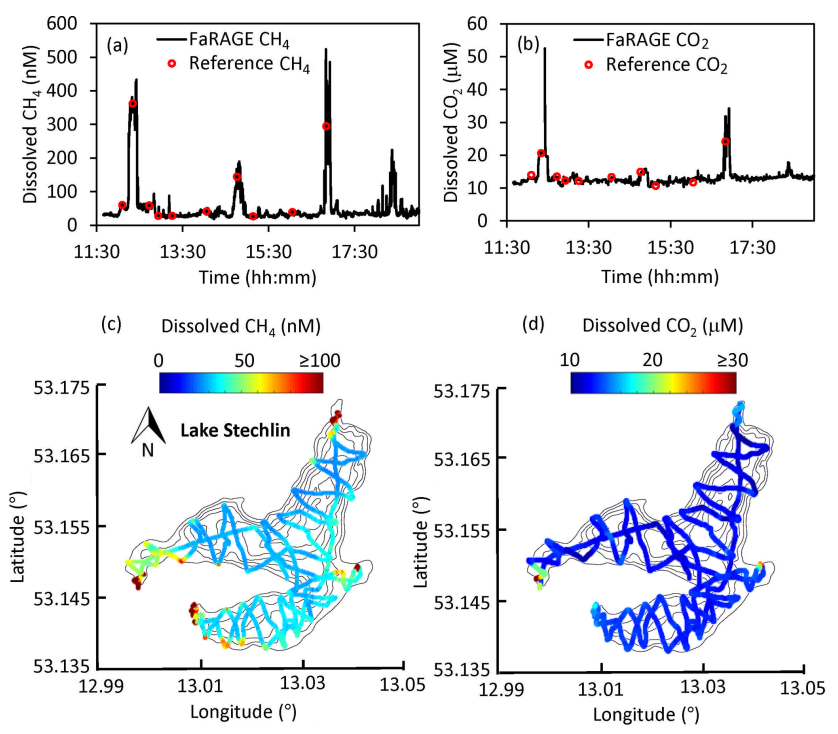

Figure 5. Map of surface dissolved $\mathrm{CH}_{4}$ concentration at Lake Stechlin. (a, b) Time series of $7 \mathrm{~h}$ continuous surface water $\mathrm{CH}_{4}$ and $\mathrm{CO}_{2}$ measurement on $28 \mathrm{March} 2019$. The reference headspace measurements are shown as red circles. (c, d) Spatial distribution of surface water $\mathrm{CH}_{4}$ and $\mathrm{CO}_{2}$ concentration is given on top of the lake's bathymetry. Colored symbols show $\mathrm{CH}_{4}$ and $\mathrm{CO}_{2}$ concentrations according to the color bars. Black lines show the outline of the lake with depth contours.

erence measurements were made at different sites and times, which were consistent with nonstop online in situ measurements. The cruising survey demonstrated the capability of this device to resolve not just vertical dynamics of $\mathrm{CH}_{4}$ and $\mathrm{CO}_{2}$ in lake water, but also the potential for studying horizontal gas distributions across large distances, for instance large lakes and rivers. With a driving speed of $5 \mathrm{~km} \mathrm{~h}^{-1}$ and a response time of $12 \mathrm{~s}$, a spatial resolution of $17 \mathrm{~m}$ can be achieved, which is sufficient for such a medium-sized lake.

\section{Comments and recommendations}

\subsection{Adaptability to different gas analyzers}

The reasons for the significantly shortened response time of the FaRAGE compared to other types of gas equilibrators are 2 -fold. While the working principle of the FaRAGE is based on the bubble-type (Schneider et al., 1992) and Weiss-type equilibrators (Johnson, 1999), a reduced headspace volume is adopted, which enhances the physical gas-water exchange. Another reason is the use of an extremely fast-response gas analyzer (Picarro Gas Scouter 4301). It is a highly recommended combination for measurement of dissolved gases when the best time-wise performance is preferred due to its great mobility (Table S2). However, coupling to other cavity ring-down gas analyzers is also possible (Table S3). This feature enables a possibility to investigate the stable isotopic nature of dissolved $\mathrm{CH}_{4}$ and $\mathrm{CO}_{2}$, which is important when sources of $\mathrm{CH}_{4}$ and $\mathrm{CO}_{2}$ need to be identified.

When a portable gas analyzer (Picarro Gas Scouter or Ultraportable Los Gatos) is used for measuring $\mathrm{CH}_{4}$ and $\mathrm{CO}_{2}$ concentrations only, the gas equilibrator can be optimized for different application environments. The length of coiled tube for gas-water mixing can be adjusted to change the response time (Fig. 3c and d). For smaller lakes a higher spatial resolution can be obtained by shortening the equilibration tubing, which shortens the response time and hence increases the spatial resolution whilst maintaining an acceptable equilibration ratio ( $51 \%$ when tube length is $1 \mathrm{~m}$ ). In environments with extremely low dissolved $\mathrm{CH}_{4}$ concentrations, e.g., ocean waters, a longer gas-water mixing tube should be used to ensure a high gas equilibration ratio.

To measure stable isotopic $\mathrm{CH}_{4}$ and $\mathrm{CO}_{2}$ in water, the sensitivity of the FaRAGE can be modified to better adapt to the choice of gas analyzer. For example, high dissolved $\mathrm{CH}_{4}$ concentrations (e.g., $\mu \mathrm{M}$-to-mM range) can be measured with greater accuracy by increasing the flow rate of the carrier gas relative to the sample water flow, therefore diluting the $\mathrm{CH}_{4}$ concentrations to the range of the gas analyzer. This can be particularly useful, for instance, when an instrument has an optimal precision at a low concentration range (1.8-12 ppm, e.g., Picarro G2201-i or G2132-i analyzers) for $\delta{ }^{13} \mathrm{C}_{-} \mathrm{CH}_{4}$ measurements. By using pure $\mathrm{N}_{2}$ gas or carrier gases (e.g., helium and argon) and corresponding gas analyzers, it would be possible to measure other dissolved trace gas concentrations, e.g., $\mathrm{N}_{2} \mathrm{O}$.

\subsection{Uncertainties due to suspended solids, temperature and pressure change}

The FaRAGE is proven to be resistant to suspended solids in freshwater lakes without having to use additional accessories. As shown in Fig. S3, apparent phytoplankton blooms were observed in the two studied lakes, each with a high biomass (Chl- $a>30 \mu \mathrm{g} \mathrm{L}^{-1}$ ) in the epilimnetic water. The measurements were unaffected, without any interruptions during measurements. As algal particles are a large component of suspended particle concentration in lakes without high suspended sediment concentration, it is safe to claim the resistance of this device to suspended solids in such systems. However, care must be taken to avoid the water intake hose hitting the bottom sediment, which could cause blockage of the water hose. An additional filtration unit for the water intake might be needed when the device is to be applied to turbid rivers.

The temperature and hydrostatic pressure could both change when water is pumped out through a water hose. To consider the temperature effect, a fast temperature logger is used (Fig. 1) which allows for corrections in calculation. Instead of using in situ lake temperature, the temperature measured at the gas equilibrator, where gas equilibration occurs, should be used. Our measurements found a minor ef- 
fect when measuring surface waters but an apparent warming for hypolimnetic water in deep lakes (Fig. S4).

The temperature correction can be made by referring to the manual headspace method. The constant gas and water flow can be used as headspace and water volume, respectively. By considering the temperature and pressure effects on gas solubility, the dissolved $\mathrm{CH}_{4}$ and $\mathrm{CO}_{2}$ concentrations can be calculated (an example calculation sheet is provided in Table S5). The calibration curve can be established using the manual headspace measurements as standards. The final concentrations can be corrected for partial equilibration by applying the equation from the calibration curve (e.g., Fig. 2a and $b$ ). The response time should be deduced when calculating $\mathrm{CH}_{4}$ and $\mathrm{CO}_{2}$ depth profiles and spatial distributions, in addition to the time lag caused by pumping water samples by using an extended water intake hose.

\subsection{Calibration, maintenance and mobility}

The FaRAGE can be readily adopted for measuring other trace gases when coupled with other portable gas analyzers. Due to differences in gas solubility (Duan and Sun, 2003; Wiesenburg and Guinasso, 1979), for each new gas, it would be necessary to establish the relative equilibration efficiency and response time, following the approach we outlined here for $\mathrm{CH}_{4}$ and $\mathrm{CO}_{2}$. Once set, a new calibration is only required when the tubing diameter or length is changed (when the old one is no longer usable due to biofilm growth). This can be done by referring to a number of known concentrations that cover a wide range (at least 5), e.g., taking water samples from different water depths of the lake or a gradient from littoral to pelagic zones. Once this full calibration is made, the calibration curve can be used for calculating the subsequent measurements. A one-point reference measurement should be performed between depth profiles or transects to check for apparent drifting. This can usually be done by taking one surface water sample from a lake for manual headspace measurement. Care should be taken when measuring in lakes with an anoxic hypolimnion where hydrogen sulfide is likely to accumulate. The performance of cavity ring-down gas analyzers can be potentially affected by $\mathrm{H}_{2} \mathrm{~S}$ (Kohl et al., 2019). At these sites, it is recommended to use a copper scrubber to remove $\mathrm{H}_{2} \mathrm{~S}$ from the gas samples (Malowany et al., 2015), and no time delay will be induced.

The gas equilibrator should be carefully maintained. Replacement of parts is recommended on a monthly basis provided the device is heavily in use. They include bubble diffusor and the coiled gas-water mixing tube. In addition, to ensure the performance and prevent biofilm formation, the gas-water mixing and separation units should be cleaned after use. Running with distilled or Milli-Q water would help to rinse the device and reduce the risk of biofilm development in the inner tubes. The performance of peristaltic pumps should also be regularly checked and the inner pump tubes need to be replaced to ensure a constant water flow.
The combination of FaRAGE with the Picarro Gas Scouter provides the most mobility. The system can be easily carried by one person and works in a small aluminum or inflatable boat where a maximum capacity of three people is possible. The device can also work in bad weather with additional measures based on protecting the gas analyzer from water damage by rain or flooding.

Data availability. An example calculation sheet (raw data of Fig. 2a) is provided as part of the Supplement for device calibration and for temperature and pressure correction when calculating dissolved methane concentration. The full data sets associated with lab and field tests are available upon request.

Supplement. The supplement related to this article is available online at: https://doi.org/10.5194/hess-24-3871-2020-supplement.

Author contributions. SX and WW proposed the idea and built the first prototype. LL improved the prototype and conducted lab and field tests. JW contributed to the field tests. AL contributed to the derivation of equations; HPG led the project and advised the development of the modified prototype. LL drafted the initial manuscript. All the authors discussed the results and commented on the manuscript.

Competing interests. The authors declare that they have no conflict of interest.

Acknowledgements. This work was financially supported by the National Natural Science Foundation of China (grant nos. 51979148 and 91647207). Liu Liu, Jason Woodhouse and Hans-Peter Grossart were financially supported by the Aquameth project of the German Research Foundation (DFG GR1540/21-1+2). We thank Andreas Jechow, Christine Kiel, Igor Ogashawara, Katrin Kohnert, Sabine Wollrab and Stella Berger for providing support with collecting field test data under project CONNECT (SAW-K45/2017) which is funded by the Leibniz Association, Germany. The authors would like to thank Hannah Geisinger and Truls Hveem Hansson for helping in collecting field data.

Financial support. This research was supported by the National Natural Science Foundation of China (grant nos. 51979148 and 91647207) and the German Research Foundation (grant no. DFG GR1540/21-1+2).

The publication of this article was funded by the Open Access Fund of the Leibniz Association.

Review statement. This paper was edited by Brian Berkowitz and reviewed by two anonymous referees. 


\section{References}

Bastviken, D., Cole, J., Pace, M., and Tranvik, L.: Methane emissions from lakes: Dependence of lake characteristics, two regional assessments, and a global estimate, Global Biogeochem. Cy., 18, GB4009, https://doi.org/10.1029/2004GB002238, 2004.

Bastviken, D., Tranvik, L. J., Downing, J. A., Crill, P. M., and Enrich-Prast, A.: Freshwater methane emissions offset the continental carbon sink, Science, 331, 50, https://doi.org/10.1126/science.1196808, 2011.

Bižić, M., Klintzsch, T., Ionescu, D., Hindiyeh, M. Y., Günthel, M., Muro-Pastor, A. M., Eckert, W., Urich, T., Keppler, F., and Grossart, H.-P.: Aquatic and terrestrial cyanobacteria produce methane, Sci. Adv., 6, eaax5343, https://doi.org/10.1126/sciadv.aax5343, 2020.

Boulart, C., Connelly, D., and Mowlem, M.: Sensors and technologies for in situ dissolved methane measurements and their evaluation using Technology Readiness Levels, Trends Anal. Chem., 29, 186-195, https://doi.org/10.1016/j.trac.2009.12.001, 2010.

Cole, J. J., Prairie, Y. T., Caraco, N. F., McDowell, W. H., Tranvik, L. J., Striegl, R. G., Duarte, C. M., Kortelainen, P., Downing, J. A., and Middelburg, J. J.: Plumbing the global carbon cycle: integrating inland waters into the terrestrial carbon budget, Ecosystems, 10, 172-185, https://doi.org/10.1007/s10021-006-9013-8, 2007.

Donis, D., Flury, S., Stöckli, A., Spangenberg, J. E., Vachon, D., and McGinnis, D. F.: Full-scale evaluation of methane production under oxic conditions in a mesotrophic lake, Nat. Commun., 8, 1661, https://doi.org/10.1038/s41467-017-01648-4, 2017.

Duan, Z. and Sun, R.: An improved model calculating $\mathrm{CO}_{2}$ solubility in pure water and aqueous $\mathrm{NaCl}$ solutions from 273 to $533 \mathrm{~K}$ and from 0 to 2000 bar, Chem. Geol., 193, 257-271, https://doi.org/10.1016/S0009-2541(02)00263-2, 2003.

Encinas Fernández, J., Peeters, F., and Hofmann, H.: Importance of the autumn overturn and anoxic conditions in the hypolimnion for the annual methane emissions from a temperate lake, Environ. Sci. Technol., 48, 7297-7304, https://doi.org/10.1021/es4056164, 2014.

Fernández, J. E., Peeters, F., and Hofmann, H.: On the methane paradox: Transport from shallow water zones rather than in situ methanogenesis is the major source of $\mathrm{CH}_{4}$ in the open surface water of lakes, J. Geophys. Res.-Biogeo., 121, 2717-2726, https://doi.org/10.1002/2016JG003586, 2016.

Frankignoulle, M., Borges, A., and Biondo, R.: A new design of equilibrator to monitor carbon dioxide in highly dynamic and turbid environments, Water Res., 35, 1344-1347, https://doi.org/10.1016/S0043-1354(00)00369-9, 2001.

Goldenfum, J. A.: GHG Measurement Guidelines for Freshwater Reservoirs, UNESCO/IHA, London, UK, 139 pp., 2010.

Gonzalez-Valencia, R., Magana-Rodriguez, F., Gerardo-Nieto, O., Sepulveda-Jauregui, A., Martinez-Cruz, K., Walter Anthony, K., Baer, D., and Thalasso, F.: In situ measurement of dissolved methane and carbon dioxide in freshwater ecosystems by off-axis integrated cavity output spectroscopy, Environ. Sci. Technol., 48, 11421-11428, https://doi.org/10.1021/es500987j, 2014.

Grossart, H.-P., Frindte, K., Dziallas, C., Eckert, W., and Tang, K. W.: Microbial methane production in oxygenated water column of an oligotrophic lake, P. Natl. Acad. Sci. USA, 108, 1965719661, https://doi.org/10.1073/pnas.1110716108, 2011.
Gülzow, W., Rehder, G., Schneider, B., v. Deimling, J. S., and Sadkowiak, B.: A new method for continuous measurement of methane and carbon dioxide in surface waters using offaxis integrated cavity output spectroscopy (ICOS): An example from the Baltic Sea, Limnol. Oceanogr.: Meth., 9, 176-184, https://doi.org/10.4319/lom.2011.9.176, 2011.

Günthel, M., Donis, D., Kirillin, G., Ionescu, D., Bizic, M., McGinnis, D. F., Grossart, H.-P., and Tang, K. W.: Contribution of oxic methane production to surface methane emission in lakes and its global importance, Nat. Commun., 10, 1-10, https://doi.org/10.1038/s41467-019-13320-0, 2019.

Hartmann, J. F., Gentz, T., Schiller, A., Greule, M., Grossart, H. P., Ionescu, D., Keppler, F., Martinez-Cruz, K., Sepulveda-Jauregui, A., and Isenbeck-Schröter, M.: A fast and sensitive method for the continuous in situ determination of dissolved methane and its $\delta^{13} \mathrm{C}$-isotope ratio in surface waters, Limnol. Oceanogr.: Meth., 16, 273-285, https://doi.org/10.1002/lom3.10244, 2018.

Hartmann, J. F., Gunthel, M., Klintzsch, T., Kirillin, G., Grossart, H.-P., Keppler, F., and Isenbeck-Schröter, M.: High SpatioTemporal Dynamics of Methane Production and Emission in Oxic Surface Water, Environ. Sci. Technol., 54, 1451-1463, https://doi.org/10.1021/acs.est.9b03182, 2020.

Hofmann, H., Federwisch, L., and Peeters, F.: Waveinduced release of methane: Littoral zones as source of methane in lakes, Limnol. Oceanogr., 55, 1990-2000, https://doi.org/10.4319/lo.2010.55.5.1990, 2010.

Hofmann, H.: Spatiotemporal distribution patterns of dissolved methane in lakes: How accurate are the current estimations of the diffusive flux path?, Geophys. Res. Lett., 40, 2779-2784, https://doi.org/10.1002/grl.50453, 2013.

Johnson, J. E.: Evaluation of a seawater equilibrator for shipboard analysis of dissolved oceanic trace gases, Anal. Chim. Acta, 395, 119-132, https://doi.org/10.1016/S0003-2670(99)00361-X, 1999.

Juutinen, S., Rantakari, M., Kortelainen, P., Huttunen, J. T., Larmola, T., Alm, J., Silvola, J., and Martikainen, P. J.: Methane dynamics in different boreal lake types, Biogeosciences, 6, 209223, https://doi.org/10.5194/bg-6-209-2009, 2009.

Kohl, L., Koskinen, M., Rissanen, K., Haikarainen, I., Polvinen, T., Hellén, H., and Pihlatie, M.: Interferences of volatile organic compounds (VOCs) on methane concentration measurements, Biogeosciences, 16, 3319-3332, https://doi.org/10.5194/bg-163319-2019, 2019.

Körtzinger, A., Thomas, H., Schneider, B., Gronau, N., Mintrop, L., and Duinker, J. C.: At-sea intercomparison of two newly designed underway $p \mathrm{CO}_{2}$ systems - encouraging results, Mar. Chem., 52, 133-145, https://doi.org/10.1016/03044203(95)00083-6, 1996.

Kreling, J., Bravidor, J., Engelhardt, C., Hupfer, M., Koschorreck, M., and Lorke, A.: The importance of physical transport and oxygen consumption for the development of a metalimnetic oxygen minimum in a lake, Limnol. Oceanogr., 62, 348-363, https://doi.org/10.1002/lno.10430, 2017.

Li, Y., Zhan, L., Zhang, J., and Chen, L.: Equilibrator-based measurements of dissolved methane in the surface ocean using an integrated cavity output laser absorption spectrometer, Acta Oceanol. Sin., 34, 34-41, https://doi.org/10.1007/s13131-0150685-9, 2015. 
Liu, R., Hofmann, A., Gülaçar, F. O., Favarger, P.-Y., and Dominik, J.: Methane concentration profiles in a lake with a permanently anoxic hypolimnion (Lake Lugano, Switzerland-Italy), Chem. Geol., 133, 201-209, https://doi.org/10.1016/S00092541(96)00090-3, 1996.

Magen, C., Lapham, L. L., Pohlman, J. W., Marshall, K., Bosman, S., Casso, M., and Chanton, J. P.: A simple headspace equilibration method for measuring dissolved methane, Limnol. Oceanogr.: Meth., 12, 637-650, https://doi.org/10.4319/lom.2014.12.637, 2014.

Malowany, K., Stix, J., Van Pelt, A., and Lucic, G.: $\mathrm{H}_{2} \mathrm{~S}$ interference on $\mathrm{CO}_{2}$ isotopic measurements using a Picarro G1101-i cavity ring-down spectrometer, Atmos. Meas. Tech., 8, 40754082, https://doi.org/10.5194/amt-8-4075-2015, 2015.

Murase, J., Sakai, Y., Sugimoto, A., Okubo, K., and Sakamoto, M.: Sources of dissolved methane in Lake Biwa, Limnology, 4, 9199, https://doi.org/10.1007/s10201-003-0095-0, 2003.

Murase, J., Sakai, Y., Kametani, A., and Sugimoto, A.: Dynamics of methane in mesotrophic Lake Biwa, Japan, Ecol. Res. 20, 377 385, https://doi.org/10.1007/s11284-005-0053-x, 2005.

Paranaíba, J. R., Barros, N., Mendonça, R., Linkhorst, A., Isidorova, A., Roland, F. B., Almeida, R. M., and Sobek, S.: Spatially resolved measurements of $\mathrm{CO}_{2}$ and $\mathrm{CH}_{4}$ concentration and gas-exchange velocity highly influence carbon-emission estimates of reservoirs, Environ. Sci. Technol., 52, 607-615, https://doi.org/10.1021/acs.est.7b05138, 2018.

Peeters, F., Fernandez, J. E., and Hofmann, H.: Sediment fluxes rather than oxic methanogenesis explain diffusive $\mathrm{CH}_{4}$ emissions from lakes and reservoirs, Sci. Rep., 9, 243, https://doi.org/10.1038/s41598-018-36530-w, 2019.

Read, J. S., Hamilton, D. P., Desai, A. R., Rose, K. C., MacIntyre, S., Lenters, J. D., Smyth, R. L., Hanson, P. C., Cole, J. J., and Staehr, P. A.: Lake-size dependency of wind shear and convection as controls on gas exchange, Geophys. Res. Lett., 39, L09405, https://doi.org/10.1029/2012GL051886, 2012.

Rhee, T., Kettle, A., and Andreae, M.: Methane and nitrous oxide emissions from the ocean: A reassessment using basinwide observations in the Atlantic, J. Geophys. Res.-Atmos., 114, D12304, https://doi.org/10.1029/2008JD011662, 2009.

Santos, I. R., Maher, D. T., and Eyre, B. D.: Coupling automated radon and carbon dioxide measurements in coastal waters, Environ. Sci. Technol., 46, 7685-7691, https://doi.org/10.1021/es301961b, 2012.

Saunois, M., Stavert, A. R., Poulter, B., Bousquet, P., Canadell, J. G., Jackson, R. B., Raymond, P. A., Dlugokencky, E. J., Houweling, S., Patra, P. K., Ciais, P., Arora, V. K., Bastviken, D., Bergamaschi, P., Blake, D. R., Brailsford, G., Bruhwiler, L., Carlson, K. M., Carrol, M., Castaldi, S., Chandra, N., Crevoisier, C., Crill, P. M., Covey, K., Curry, C. L., Etiope, G., Frankenberg, C., Gedney, N., Hegglin, M. I., Höglund-Isaksson, L., Hugelius, G., Ishizawa, M., Ito, A., Janssens-Maenhout, G., Jensen, K. M., Joos, F., Kleinen, T., Krummel, P. B., Langenfelds, R. L., Laruelle, G. G., Liu, L., Machida, T., Maksyutov, S., McDonald, K. C., McNorton, J., Miller, P. A., Melton, J. R., Morino, I., Müller, J., Murguia-Flores, F., Naik, V., Niwa, Y., Noce, S., O’Doherty, S., Parker, R. J., Peng, C., Peng, S., Peters, G. P., Prigent, C., Prinn, R., Ramonet, M., Regnier, P., Riley, W. J., Rosentreter, J. A., Segers, A., Simpson, I. J., Shi, H., Smith, S. J., Steele, L. P., Thornton, B. F., Tian, H., Tohjima, Y., Tubiello,
F. N., Tsuruta, A., Viovy, N., Voulgarakis, A., Weber, T. S., van Weele, M., van der Werf, G. R., Weiss, R. F., Worthy, D., Wunch, D., Yin, Y., Yoshida, Y., Zhang, W., Zhang, Z., Zhao, Y., Zheng, B., Zhu, Q., Zhu, Q., and Zhuang, Q.: The Global Methane Budget 2000-2017, Earth Syst. Sci. Data, 12, 15611623, https://doi.org/10.5194/essd-12-1561-2020, 2020.

Schlüter, M. and Gentz, T.: Application of membrane inlet mass spectrometry for online and in situ analysis of methane in aquatic environments, J. Am. Soc. Mass Spectrom., 19, 1395-1402, https://doi.org/10.1016/j.jasms.2008.07.021, 2008.

Schneider, B., Kremling, K., and Duinker, J. C.: $\mathrm{CO}_{2}$ partial pressure in Northeast Atlantic and adjacent shelf waters: Processes and seasonal variability, J. Mar. Syst., 3, 453-463, https://doi.org/10.1016/0924-7963(92)90016-2, 1992.

Stepanenko, V., Mammarella, I., Ojala, A., Miettinen, H., Lykosov, V., and Vesala, T.: LAKE 2.0: a model for temperature, methane, carbon dioxide and oxygen dynamics in lakes, Geosci. Model Dev., 9, 1977-2006, https://doi.org/10.5194/gmd-9-1977-2016, 2016.

Tang, K. W., McGinnis, D. F., Frindte, K., Brüchert, V., and Grossart, H.-P.: Paradox reconsidered: Methane oversaturation in well-oxygenated lake waters, Limnol. Oceanogr., 59, 275-284, https://doi.org/10.4319/lo.2014.59.1.0275, 2014.

Tranvik, L. J., Downing, J. A., Cotner, J. B., Loiselle, S. A., Striegl, R. G., Ballatore, T. J., Dillon, P., Finlay, K., Fortino, K., and Knoll, L. B.: Lakes and reservoirs as regulators of carbon cycling and climate, Limnol. Oceanogr., 54, 2298-2314, https://doi.org/10.4319/lo.2009.54.6_part_2.2298, 2009.

Vachon, D. and Prairie, Y. T.: The ecosystem size and shape dependence of gas transfer velocity versus wind speed relationships in lakes, Can. J. Fish. Aquat. Sci., 70, 1757-1764, https://doi.org/10.1139/cjfas-2013-0241, 2013.

Webb, J. R., Maher, D. T., and Santos, I. R.: Automated, in situ measurements of dissolved $\mathrm{CO}_{2}, \mathrm{CH}_{4}$, and $\delta^{13} \mathrm{C}$ values using cavity enhanced laser absorption spectrometry: Comparing response times of air-water equilibrators, Limnol. Oceanogr.: Meth., 14, 323-337, https://doi.org/10.1002/lom3.10092, 2016.

Weiss, R. F.: Carbon dioxide in water and seawater: the solubility of a non-ideal gas, Mar. Chem., 2, 203-215, https://doi.org/10.1016/0304-4203(74)90015-2, 1974.

Wiesenburg, D. A. and Guinasso Jr., N. L.: Equilibrium solubilities of methane, carbon monoxide, and hydrogen in water and sea water, J. Chem. Eng. Data, 24, 356-360, https://doi.org/10.1021/je60083a006, 1979.

Zimmermann, M., Mayr, M. J., Bouffard, D., Eugster, W., Steinsberger, T., Wehrli, B., Brand, A., and Bürgmann, H.: Lake overturn as a key driver for methane oxidation, preprint: bioRxiv, https://doi.org/10.1101/689182, 2019. 